\title{
A CRIAÇÃO DO ENSINO DE ENFERMAGEM NO BRASIL
}

[The creation of the nursing teaching in Brazil]

Denise Faucz Kletemberg* Márcia T. A. Dalledone Siqueira**

RESUMO: A retrospectiva histórica permite a análise dos fatos ocorridos de maneira crítica e reflexiva, procurando respostas a questionamentos que permeiam a prática contemporânea da Enfermagem. Aimposição do mercado de trabalho, a dicotomia teoria-prática, o cuidado centrado apenas no saber-fazer, a submissão da categoria e sua conseqüente falta de autonomia possuem raízes históricas na construção profissional da categoria, tanto na prática como no ensino. Assim, apresenta-se uma análise histórica do Decreto $\mathrm{n}^{\circ}$ 791 , de 27 de setembro de 1890, assinado pelo então presidente da República, Marechal Deodoro da Fonseca, momento em que se criou a primeira escola de Enfermagem no Brasil. A análise e contextualização histórica do documento permitem vislumbrar que a ênfase no tecnicismo, a criação de mão-de-obra barata e a subserviência, já eram questões presentes no ensino da Enfermagem no país desde seus primórdios.

PALAVRAS-CHAVE: História da Enfermagem; Educação em Enfermagem; Legislação.

\section{INTRODUÇÃO}

A Enfermagem vem progredindo expressivamente, buscando firmar-se como detentora de saber científico, sem deixar de lado o aspecto humanitário de sua profissão. De Florence Nightingale ao mundo contemporâneo, seu trabalho tem-se especializado cada vez mais,

\footnotetext{
*Enfermeira. Mestranda do Programa de Pós-graduação em Enfermagem da Universidade Federal do Paraná. Bolsista de Pósgraduação da CAPES. Membro do Grupo de Estudos Multiprofissional em Saúde do Adulto - GEMSA

**Historiadora. Doutora em História. Professora do Departamento de História da Universidade Federal do Paraná.
}

pois não há mais espaço exclusivo apenas para a puericultura e a higiene, que outrora compunham o contexto dos cuidados a serem desenvolvidos pelos profissionais dessa área. Seu campo de trabalho aumenta cada vez mais, indo da orientação nas escolas e postos de saúde aos estudos nas diversas especificidades do cuidado.

Os saberes próprios da Enfermagem foram forjados na prática e na observação atenta, no somatório de experiências, nas respostas certas para os inúmeros desafios e na permanente construção de novos conhecimentos. Esse processo dialético levou a muitos caminhos, o que pode ser resgatado ao privilegiar-se a perspectiva da análise histórica.

As variações conjunturais no modelo políticoeconômico brasileiro, ao longo do século XIX, tiveram implicações diretas no setor de saúde. A presença constante de doenças epidêmicas no país dificultava as negociações dos produtos brasileiros, destinados a exportação. Esta situação levou a uma política de controle de doenças epidêmicas, a necessidade de profissionais capacitados e treinados para a prestação dos serviços, a vigilância sanitária dos portos, e ao cuidado com os dentes. E neste contexto que ocorre a institucionalização da educação de Enfermagem no Brasil.

Assim, este estudo tem por objetivo fazer análise histórica do Decreto $\mathrm{n}^{\circ} 791$, de 1890 , que instituiu a primeira escola de Enfermagem no Brasil. Esta análise é pautada no método histórico, com base em dados documentais e bibliográficos. Busca não só o Decreto em si, mas as características do curso criado, refletindo a prática do cuidado dos profissionais da área. 


\section{A SAÚDE NO BRASIL NO SÉCULO XIX}

No Brasil, desde a colonização, as epidemias grassaram livremente, atingindo principalmente os centros urbanos. Os recursos destinados à saúde eram precários ou quase inexistentes. A medicina no Brasil era em grande parte exercida por barbeiros, cirurgiões barbeiros e físicos. "Extensas regiões do país, povoadas sem conta não tinham sequer um barbeiro para as sangrias e primeiros socorros. O povo tomava qualquer viajante estrangeiro como médico e logo acorria implorando um exame" (SANTOS FILHO, 1947). Se no caso da Medicina a situação era dramática, o que se poderia dizer então, dos serviços de atendimento e cuidados aos doentes. Esses, em sua maioria, ficavam ao encargo das próprias famílias, na figura da "mãe"; ou de iniciativas caritativas, como as Santas Casas de Misericórdia e as ordens religiosas, seguindo o modelo português.

A chegada de profissionais de saúde estrangeiros, a partir de 1808 , foi impulsionada pela vinda da Corte portuguesa que se instalou no Brasil fugindo das tropas napoleônicas. A família real, contando com a ajuda inglesa, transferiu-se com cerca de 20 mil pessoas, trazendo consigo várias instituições metropolitanas, reproduzindo no Brasil o aparelho administrativo do Estado português.

As cidades brasileiras não estavam aparelhadas para receber o contingente de nobres e burgueses que vieram junto com D. João VI. Assim, o espaço urbano precisava ser reestruturado para evitar os perigos das epidemias. Havia a necessidade de cuidados de saúde para atender às elites, bem como os portos precisavam ser mantidos em boas condições sanitárias para garantir os interesses econômicos do Estado (LUZ, 1982).

Foi, sobretudo com a transferência da Corte para a cidade do Rio de Janeiro, que teve início a história institucional da ciência no país. Com a criação de Escolas profissionais de medicina e engenharia militar, um horto, uma casa de História Natural. Além de outras instituições culturais: uma biblioteca e uma escola de belas artes, entre outras. Eram modelos institucionais tradicionalmente reconhecidos nos países europeus e que, além de seu valor cultural, eram vistos pela Coroa, como essenciais para uma exploração mais sistemática das riquezas coloniais (DANTES, 1995).

Portanto, era necessário adequar o espaço urbano às novas exigências políticas, econômicas e sociais diante do perigo epidêmico, o qual era identificado com a desordem urbana. Reconhecendo também a necessidade de maior número de profissionais na área da saúde, o governo da colônia criou através de Carta Régia em 1808, a Escola de Cirurgia de Salvador - na Bahia, e depois a do Rio de Janeiro. Fundamentado nos compêndios franceses, o ensino deveria constar de aulas teóricas e demonstrações práticas nas enfermarias das Santas Casas e do Hospital Real Militar (LUZ, 1982).

Entretanto, a prática da saúde continuou ao longo do século XIX, muito semelhante à dos séculos anteriores. Alguns ramos pouco se desenvolveram, entre eles, a patologia, a terapêutica, a cirurgia e a obstetrícia. A assistência hospitalar era deficiente. Doenças como a varíola, que reinou de forma epidêmica, mataram um contingente significativo da população. A febre amarela apresentou vários surtos epidêmicos. A malária, o cólera e o tifo também estiveram presentes. Enfim, predominavam as chamadas "doenças tropicais".

A prevalência das doenças infectocontagiosas e a falta de higiene nos portos acarretavam resistência à chegada de navios, contrapondo-se aos interesses da economia exportadora cafeeira.

Assim, na primeira metade do século XIX, iniciou-se a organização da higiene pública, segundo Germano (1983), impulsionada pela epidemia de febre amarela em meados de 1850, que ceifara a vida de quatro mil pessoas. Em resposta ao pedido do Ministro do Império à Academia Imperial de Medicina, da elaboração de um plano para combater essa epidemia, algumas medidas sanitárias foram reativadas, como: a existência de um órgão dirigente da saúde pública, a divisão da cidade em paróquias e distritos para maior organização sanitária, o serviço de assistência gratuita aos pobres e a inspeção sanitária em navios, mercados, prisões, hospitais e colégios. Essas providências porém, tiveram pouco impacto em relação às precárias condições de vida da maioria da população, persistindo ainda o grave problema das epidemias, contrastando com os avanços científicos alcançados pela 
medicina e a biologia de então.

Só no final do século, as alterações foram sentidas na prática dos serviços de saúde, que passaram, cada vez mais, a se ocupar do corpo social. Conforme se refere Luz (1982): "Com a criação das escolas médicas, criou-se um espaço institucional indispensável à reprodução do saber médico, que busca criar uma consciência higiênica do povo e excluir os charlatões das práticas curativas".

A persistência do problema das epidemias se arrastou pelo país até as primeiras décadas do século $X X$, constituindo-se em um entrave às relações comerciais e econômicas, tanto nacionais como internacionais. Neste contexto, segundo Germano (1983), o sanitarista Oswaldo Cruz foi convidado pelo governo a empreender uma campanha para controlar a febre amarela no Rio de Janeiro, combatendo paralelamente a varíola e a peste.

Ainda segundo Germano (1983), "é nesse quadro que emerge o ensino sistematizado da Enfermagem, com o propósito de formar profissionais que contribuíssem para o saneamento dos portos", como a criação da escola Anna Nery, em 1923. Imprime-se assim no discurso oficial, a caracterização histórica dos primórdios do ensino de Enfermagem no Brasil, na área de saúde pública, a fim de garantir o saneamento dos portos.

No entanto, sabe-se historicamente que a primeira escola voltada para a assistência hospitalar foi criada no final do século XIX, junto ao Hospital de Alienados no Rio de Janeiro.

\subsection{A PRIMEIRA ESCOLA DE ENFERMAGEM NO BRASIL}

O ensino de Enfermagem foi oficialmente instituído no Brasil com a criação da Escola Profissional de Enfermeiros e Enfermeiras, conforme o Decreto Federal $n^{\circ} 791$, de 27 de setembro de 1890, do Governo Provisório da República dos Estados Unidos do Brasil (RESENDE, 1961). Posteriormente, esta escola passou a ser denominada Escola de Enfermagem Alfredo Pinto.

Na literatura de Enfermagem, contudo, vários documentos apresentam a Escola Anna Nery, fundada em 1923, como a primeira escola de Enfermagem do Brasil. Isso é justificado por ter sido esta a primeira a funcionar genuinamente sob a orientação e organização de enfermeiras, como esclarece Germano (1983), diferentemente da Escola de Enfermeiros e Enfermeiras, cujo quadro docente era composto por médicos e supervisores do Hospital a ela filiado.

A escola surgiu diante da necessidade de formar pessoal qualificado para o atendimento aos enfermos do Hospital Nacional de Alienados do Rio de Janeiro, instituição que havia sido abandonada pelas irmãs de caridade.

$\mathrm{O}$ atendimento à pacientes psiquiátricos sempre despertou a atenção das autoridades, tanto dos médicos como dos religiosos e leigos. Assim, a necessidade de uma instituição para o abrigo específico de doentes mentais se fazia presente, pois todos aqueles que apresentassem problemas de loucura eram confinados em prisões, como criminosos, ou confinados a celas em instituições de saúde, tratados inadequadamente e por vezes sob torturas físicas. Segundo Moreira (2002), para a sociedade era conveniente a restrição destes do convívio social, devendo ser construídos para eles asilos e abrigos afastados dos centros urbanos. Assim, em 1841, D. Pedro II criou no Rio de Janeiro o Hospício Pedro II, localizado na Chácara do Vigário Geral, de propriedade da Santa Casa de Misericórdia. As obras tiveram início em 1842, vindo a funcionar dez anos depois, com 144 pacientes hospitalizados.

Havia grades, celas de isolamento, quartos fortes, mas existia um esboço de tratamento ocupacional, com instrumentos de música, oficinas para trabalhos manuais e, sobretudo, claridade e pátios arborizados. Após a construção do novo prédio, o Ministro do Governo Provisório, Aristides Lobo, pelo Decreto 162-A, de 11 de janeiro de 1890, determinava a desanexação do hospício e suas colônias da Santa Casa de Misericórdia. Passou então a denominarse Hospital Nacional de Alienados (MOREIRA, 2002).

Foi então designado, como Diretor Geral, o Dr. João Carlos Teixeira Brandão, que implementou mudanças na instituição, dentre elas a destituição do poder das irmãs de caridade que prestavam assistência aos hospitalizados. Desprestigiadas, essas abandonaram o hospital gerando descontinuidade na assistência aos hospitalizados. A solução foi a contratação de enfermeiras leigas, européias, para substituí-las. 
Apesar da crise econômica enfrentada pela República, gerando drástica redução orçamentária no governo de Campos Sales, a solicitação do diretor do Hospital de Alienados foi atendida. Ele propunha a contratação de enfermeiras de Salpêtrière (França), cujo contrato foi firmado entre o Ministro da França e o do Brasil, com vigência de dois anos, de fevereiro de 1893 a fevereiro de 1895. Esse episódio expôs o confronto entre o poder laico e o poder clerical, demonstrando a supremacia do Estado no controle assistencial.

Diante da situação, Moreira (2002) esclarece que:

Com um discurso psiquiátrico de melhoria da assistência, a situação em que ficou o serviço do hospício, com a saída das religiosas e a falta de mãode-obra para assumir os trabalhos - foi vislumbrada a possibilidade de se solucionar o problema. Tendo em vista a deficiência de infra-estrutura no funcionamento hospitalar e na assistência exercida pelo pessoal não qualificado, apesar das medidas tomadas, frutificou a idéia da criação de uma escola para preparar o pessoal de Enfermagem para o Hospital Nacional de Alienados e os hospitais civis e militares do Rio de Janeiro (MOREIRA, 2002).

Fica evidente o paradoxo, num contexto social de epidemias atingindo parte significativa da população, a primeira escola para formação de profissionais em enfermagem surgiu em decorrência da mobilização política da classe médica e da elite burocrática. Confrontavam-se assim, o poder eclesiástico representado pelas irmãs de caridade, que detinham a autoridade dentro da instituição hospitalar, e o próprio Estado.

A justificativa da criação da escola para o preparo de pessoal qualificado às funções de enfermagem também foi sugerida como solução para a inserção do contingente feminino, mantido em orfanatos públicos e filantrópicos, no mercado de trabalho. Esse aspecto é referendado por José Cesário de Faria Alvin, ao apontar novos horizontes à mão-de-obra feminina:

Em regra, não encontrando applicação immediata e remunerada para sua actividade educada, ou conservam-se nos estabelecimentos que as preparam e que as não despedem, perdendo assim tempo e impedindo o recebimento de outras necessitadas, ou se unem por casamentos desiguaes que quase nunca a mutua affeição determina, pelo que se constituem novas fontes de gerações infelizes, que voltam mais tarde aos pontos de agazalho dos seus progenitores.

A escola de enfermeiras, pois, que o decreto que vos offereço tende a crear, abre, me parece, um campo vastíssimo á actividade da mulher, onde, por sua delicadeza de sentimentos e apuro de carinhos, não terá competidores, quer junto aos leitos dos enfermos hospitalares, quer nas casas particulares onde serão o complemento do médico (BRASIL, 1890).

Esse processo culminou em um decreto federal, que definiu a formação e as qualificações próprias para o profissional de enfermagem.

\subsection{LEGALIZANDO O OFÍCIO}

O Decreto Federal $n^{\circ} 791$ de 27 de setembro de 1890, criou oficialmente a primeira escola de enfermagem no Brasil. Apresentado em oito artigos, dispunha sobre o ensino e a prática da assistência no país.

No seu primeiro artigo, instituiu no Hospício Nacional de Alienados uma escola destinada a preparar enfermeiros e enfermeiras para atuar nos hospícios e hospitais civis e militares. Assim, trouxe para a alçada do Estado a responsabilidade de formar mão-de-obra qualificada para prestar assistência aos enfermos em diferentes serviços e instituições. Contrariando desta forma a prática usual, que até então consistia no recrutamento de pessoas abnegadas, de boa-vontade e imbuídas de espírito caritativo, a exemplo das ordens e instituições religiosas, que eram responsáveis pelo treinamento de pessoal e pela supervisão da prestação dos cuidados aos enfermos.

O segundo artigo dispunha sobre as disciplinas a serem ministradas:
Art. $2^{\circ} \mathrm{O}$ curso constará:
$1^{\circ}$, de noções práticas de propedêutica clínica;
$2^{\circ}$, de noções geraes de anatomia, physiologia, hygiene hospitalar, curativos, pequena cirurgia, cuidados especiaes a certas categorias de enfermos e applicaçoes balneotherapicas;
$3^{\circ}$, de administração interna e escripturação do serviço sanitário e econômico das enfermarias.

Observa-se que as disciplinas elencadas apontam prioritariamente para a formação de uma visão hospitalar, em virtude da carência de profissionais qualificados no país. Entre os profissionais atuantes, o destaque era para as congregações 
religiosas, proporcionando um espaço de poder e hegemonia eclesiástica, muitas vezes rivalizando com as determinações e gerenciamentos oficiais.

O currículo do curso era exclusivamente voltado para a assistência hospitalar, o que evidenciava uma contradição, pois apesar da preocupação governamental com as políticas de saúde pública para a contenção das epidemias, a formação profissional foi forjada pelas necessidades de atendimento ao paciente psiquiátrico. Isso se deveu às articulações políticas, às recomendações médicas, bem como ao apoio da população, que pressionava pela retirada dos alienados e mendigos dos centros urbanos.

O terceiro artigo dispunha sobre a metodologia pedagógica.

Art. $3^{\circ}$ os cursos theóricos se effectuarão tres vezes por semana, em seguida a visita as enfermarias, e serão dirigidos pelos internos e inspectoras, sob fiscalização do médico e superintendência do director geral.

Aqui se percebe a lógica positivista, compreendida na nacionalidade do ensino teórico e a posterior aplicação na prática assistencial, seguindo o modelo francês que orientava também as escolas de medicina. Encontram-se, desde os primórdios do ensino da Enfermagem no Brasil, evidências da divisão entre teoria e prática, cuja permanência e questionada e sentida até hoje, pelos profissionais da área.

O conteúdo teórico era ensinado pelos próprios médicos, os quais forneciam noções elementares para o bom desempenho profissional. Cabia a tarefa prática de supervisão às inspetoras, neste caso, as enfermeiras francesas contratadas, pela instituição:

[...], tendo sido a escola criada em 1890 , beneficiouse dos préstimos e orientações das enfermeiras francesas, uma vez que, do ponto de vista da autonomia administrativa e econômica, era mantida a sombra das injunções do Hospital Nacional de Alienados, o qual funcionava em condições precárias (MOREIRA, 2002).

Portanto, havia uma divisão de tarefas, bem como uma rígida hierarquia de controle, sob a fiscalização do direito hospitalar.

O quarto artigo determinava as condições para as matrículas. Elas deveriam respeitar os seguintes aspectos: o candidato deveria ser maior de 18 anos; saber ler e escrever corretamente, conhecer aritmética elementar e apresentar atestado de "bons costumes".

O pré-requisito de alfabetizado transparecia no nível de desempenho esperado deste profissional. Um trabalhador voltado para o saber fazer, para prestar assistência aos alienados de maneira simples e sem questionamentos. O pedido do atestado de "bons costumes" remete à reminiscência histórica, presente desde o final da Idade Média. Tratava-se de uma certidão, emitida pelas autoridades locais, informando sobre o comportamento de determinada pessoa.

O mesmo artigo fazia alusão à "bolsatrabalho", podendo admitir alunos internos e externos, sendo que os primeiros não poderiam exceder o número de 30 . Além de aposento e alimentação, tinham direito à gratificação no primeiro ano, expressos na quantia de vinte mil reis (20\$) mensais; no segundo ano, depois da primeira aprendizagem, de $25 \$$. Deveriam ainda, trabalhar em conjunto com os empregados do estabelecimento no serviço que Ihes fosse designado. Asseguravam-se assim, trabalhadores para o Hospital de Alienados, desde o segundo ano de implementação da escola.

Este artigo, que trata das matrículas, curiosamente não estabelece o número de vagas existentes, porém fixa o número de alunos internos, o que demonstra que já havia esta possibilidade desde a turma inaugural, demonstrando a intenção da criação da escola, ou seja, preparo e treinamento de pessoal que prestasse serviços ao Hospital de Alienados.

Em seu quinto artigo, o Decreto conferia prêmios de $50 \$$ (mil reis) aos alunos que se destacassem nos exames. O estímulo financeiro em premiar os melhores alunos seria um incentivo ao estudo ou a preocupação dos dirigentes do Hospital com a qualidade da formação? São, sem dúvida, aspectos instigantes que merecem reflexões futuras, pois não se conhecem registros sobre esse fato.

O mesmo artigo prossegue:

[...] aos enfermeiros diplomados e alumnos que em qualquer tempo se invalidarem no exercício da profissão em hospitais mantidos pelo Estado, por effeito dos deveres a ella inherentes, se abonará uma pensão proporcional ao ordenado que perceberem. 
Esta é uma preocupação nova para o Estado, pois ao remunerar o trabalhador na área de saúde, deveria prever pensões quando estes estivessem impossibilitados de exercer o ofício; preocupação esta inexistente, quando o cuidado de enfermagem estava sob responsabilidade das congregações religiosas. Denota-se assim, uma política trabalhista, que visava a manutenção do serviço e assegurava as condições do profissional.

Moreira (2002) considera que embutido nos aspectos trabalhistas está o controle social do profissional da enfermagem, ao afirmar que:

Podemos dizer que a Enfermagem, no Brasil, teve como pano de fundo do processo de institucionalização de seu ensino as funções de preservação, manutenção e conservação da força de trabalho, constituindo-se simultaneamente, também, em força de trabalho barata, mas imprescindível a implementação do projeto de controle social, que se estabelecia com a participação da psiquiatria (MOREIRA, 2002)

O artigo sexto dispunha sobre a duração do curso, que poderia ser realizado, no mínimo, em dois; cabendo ao diretor geral da Assistência Legal dos Alienados conferir o diploma. Isso sugere indiretamente a carência de profissionais na área e a necessidade da rápida habilitação, minimizando desta forma, a precária situação de atendimento aos doentes nos serviços de saúde.

Em seu sétimo artigo, o diploma estabelecia a preferência para os empregos em hospitais mantidos pelo Estado e previa aposentadoria aos 25 anos de exercício profissional, de acordo com as leis vigentes então. Com a carência de profissionais capacitados no mercado, o Decreto parece mascarar a verdadeira intenção dos criadores da escola a serviço do Estado, qual seja, direcionar os egressos para os serviços públicos, oferecendo reserva de vagas para estes, garantindo o retorno do profissional.

Os aspectos disciplinares são tratados no oitavo artigo, ficando os alunos sujeitos às penas disciplinares impostas nas instruções do serviço interno do Hospital de Alienados aos seus empregados.

\section{CONSIDERAÇÕES FINAIS}

A enfermagem, desde suas origens institucionais na sociedade brasileira do século XIX, apresenta-se como uma forma do Estado intervir diretamente nas ações do cuidar. Portanto, não pode ser desligada do contexto histórico em que foi produzida, face às condições de saúde da população e aos movimentos sociais que se organizaram em torno da questão da saúde no Brasil.

Embora o processo histórico apresente diversas conjunturas, e no momento das crises epidêmicas que eles se manifestaram plenamente. Nestes momentos, novos mecanismos de controle são pensados e postos em prática.

A institucionalização do ensino da enfermagem representou não só a ampliação do campo de atuação da enfermagem, como também, o reconhecimento da profissão pelo Estado, ao nível formal. Esse processo de normalização, embora de interesse do Estado, encontrou resistências na prática, por parte das antigas instituições responsáveis pelos serviços.

Assim ocorreu com a Escola Profissional de Enfermeiros e Enfermeiras do Rio de Janeiro, que oficialmente veiculou, num primeiro momento, os modelos de saber da enfermagem, a serem difundidos no país. Entretanto, não fica evidente dentro da categoria profissional um projeto de afirmação de poder ou de formação, uma vez que se traduziu numa imposição medica da alçada do governo, portanto externa aos profissionais da enfermagem. Contudo, fica clara a intenção do Estado em excluir a Igreja da formação e execução das práticas do cuidado.

Apesar do Decreto $n^{\circ} 791 / 1890$ representar um avanço para a regulamentação e valorização da prática da Enfermagem no Brasil, fica claro o seu enfoque prioritariamente biologicista. Fato este determinado pela lógica do mercado de trabalho da época, ou seja, formar profissionais voltados para prestar a assistência, o cuidado com o doente hospitalizado e a integração no serviço, respeitando-se a hierarquia institucional.

O Decreto também traz impresso o pensamento dos detentores do poder, quanto à formação da categoria, colocando a ênfase no saber-fazer, sob o controle de uma hierarquia, subalterna aos demais profissionais e serviços. Esta visão do profissional da enfermagem ainda permanece cristalizada em determinados centros 
e serviços, subjugando a enfermagem à medicina e às instituições empregadoras.

A ruptura desse processo, do saber-fazer para o saber-ser enfermeiro, a busca da cientificidade, traduz-se hoje em verdadeiro anacronismo, a proplada dicotomia teoria-prática, dado aos avanços científicos obtidos na área e na maneira holística de se abordar o paciente. Sem dúvida, a quebra desse modelo demandou uma tomada de consciência e de valorização do profissional da Enfermagem, que no mundo contemporâneo busca estabelecer uma identidade própria no contexto social e histórico em que se desenvolve a profissão, no âmbito dos cuidados da área de saúde no país.

ABSTRACT: The historical retrospective allows the analysis of the facts in a critical and reflexive way, looking for answers to questions that arise in the comtemporary Nursing prctice. The theory-practice dichotomy, the care centered only in know-how-tomake, the submission of the category and its consequent lack of autonomy have historical roots in the professional construction of Nursing, in its practice as well as in the teaching process. We present an analysis of the $n^{\circ} 791$ Decree signed by Marechal Deodoro da Fonseca, president of the Brazilian Republic at the time, which isntitued the fist school of Nursing in Brazil. The analysis of such decue in its historical context allow us to infer that teaching of Nursing in Brazil emphasizes the technical aspects since then.

KEY WORDS: Nursing History; Nursing Education; Legislation.

\section{REFERÊNCIAS}

BRASIL. Decretos do governo Provisório da República dos Estados Unidos do Brasil. $9^{\circ}$ fascículo. Rio de Janeiro: Imprensa Nacional, 1890.

DANTES, M. A. Relações científicas e tradições locais. In: GOLDFARD, A. M.; MAIA, C. História da Ciência. São Paulo: Edusp, 1995. p. do capítulo.

GERMANO, R. M. Educação e ideologia da Enfermagem no Brasil. São Paulo: Cortez, 1983. cuidado como manifestação do ser e fazer na Enfermagem. Vidya. Santa Maria, v. 1, n. 1, jul/ dez. 1996.

LUZ, M. T. Medicina e ordem política brasileira. Rio de Janeiro: Graal, 1982.

MOREIRA, A. A primeira escola de enfermagem. In: GEOVANINI, T. et al. História da Enfermagem: versões e interpretações. 2. ed. Rio de Janeiro: Revinter, 2002.

RESENDE, M. A. Ensino de Enfermagem. Revista Brasileira de Enfermagem. Rio de Janeiro, v. 15, n. 2, p. 110-158, abr. 1961.

SANTOS FILHO, L. História da Medicina no Brasil. São Paulo: Brasiliense, 1947.

SILVA, G. B. A Enfermagem profissional: análise crítica. São Paulo: Cortez, 1986.

SORDI, M. R. L.; BAGNATO, M. H. S. Subsídios para uma formação profissional crítico-reflexiva na área de saúde: o desafio na virada do século. Revista Latino-americana de enfermagem, Ribeirão Preto, v. 6, n. 2, p. 83-88, 1998.

ENDEREÇO DAS AUTORAS: Rua Pedro Collere, 684 Curitiba/PR 80320-320 